\title{
Estudio de los cambios de la composición química de un ionómero vítreo mediante la técnica de PIXE
}

\author{
María Gisela Verón ${ }^{1}$, Sergio Gabriel Suárez ${ }^{1,2,3}$, \\ Miguel Oscar Prado ${ }^{1,2,3}$
}

\author{
${ }^{1}$ Consejo Nacional de Investigaciones Científicas y Técnicas, Buenos Aires, Buenos Aires, Argentina. \\ ${ }^{2}$ Centro Atómico Bariloche - Comisión Nacional de Energía Atómica, Bariloche, Río Negro, Argentina. \\ ${ }^{3}$ Instituto Balseiro (Universidad Nacional de Cuyo - Comisión Nacional de Energía Atómica), Bariloche, Río Negro, \\ Argentina. \\ e-mail: maria.gisela.veron@cab.cnea.gov.ar; suarez@cab.cnea.gov.ar; pradom@cab.cnea.gov.ar
}

\section{RESUMEN}

En el presente trabajo se estudia el efecto de bebidas de consumo habitual como café, mate, té y agua mineral en la composición química de la superfície de un ionómero de vidrio comercial. Las muestras de ionómero se prepararon según las indicaciones del fabricante; se colocaron en las infusiones y se estacionaron en estufa de cultivo a $36{ }^{\circ} \mathrm{C}$ en el rango de 21 horas hasta 33 días. La evolución de la composición química a diferentes tiempos de almacenamiento se estudió mediante la técnica de Emisión de Rayos X inducida por Protones (PIXE). En todos los medios, excepto agua mineral, a tiempos largos se determinó la pérdida de Al, Si y Na, esto sugiere la disolución parcial de un aluminosilicato de $\mathrm{Na}$. El perfil de concentración de Al y Si fue diferente en todos los medios, pero la relación Al:Si se mantuvo cercana a la unidad en todos los casos. El F se liberó asociado con $\mathrm{Na}$ en agua mineral, mientras que en el resto de bebidas su perfil de concentración infiere la formación de compuestros fluorados de Ca y La. Simultáneamente se observó la incorporación de $\mathrm{Mn}, \mathrm{Mg}$ y Fe en la superficie del ionómero vítreo, no reportada anteriormente en la literatura.

Palabras clave: Materiales dentales, ionómeros vítreos, PIXE.

\begin{abstract}
In the present work, the effect of commonly consumed beverages such as coffee, mate, tea and mineral water on the surface chemical composition of a commercial glass ionomer is studied. Ionomer samples were prepared according to the manufacturer; they were placed within infusions and stationed on culture stove at $36^{\circ}$ $\mathrm{C}$ in the range of 21 hours to 33 days. The evolution of the chemical composition at different storage times was studied by Proton Induced X-Ray Emission (PIXE) technique. In all media except mineral water, to long times, the loss of $\mathrm{Al}, \mathrm{Si}$ and $\mathrm{Na}$ was determined, suggesting the partial dissolution of $\mathrm{Na}$ aluminumsilicate. The concentration profile of $\mathrm{Al}$ and $\mathrm{Si}$ were different in every way, but the ratio $\mathrm{Al}$ : Si remained close to unity in all cases. The $\mathrm{F}$ was released associated with $\mathrm{Na}$ in mineral water, while in the rest of the beverages its concentration profile infers the formation of fluorinated compounds of $\mathrm{Ca}$ and La. Simultaneously, the adsorption of $\mathrm{Mn}, \mathrm{Mg}$ and $\mathrm{Fe}$ to the glass ionomer surface was observed, not previously reported in the literature.
\end{abstract}

Keywords: Dental materials, glass ionomers, PIXE.

\section{INTRODUCCIÓN}

En la actualidad, los ionómeros de vidrio (IV) constituyen uno de los materiales más versátiles, con una variedad de aplicaciones en la odontología moderna [1,2].

El cemento original fue desarrollado EN 1969 por WILSON y KENT [3], y ha sido objeto de continua mejora y diversificación $[1,2,4,5]$. Estos materiales resultan de la reacción ácido-base entre una fase vítrea de fluoraluminosilicato y una fase orgánica a base de ácidos polialquenoicos en suspensión acuosa [1-11]. El cemento resultante es una red orgánica/inorgánica que se adhiere a la estructura dental y es traslúcida [1-13]. Entre sus propiedades más importantes se destacan la adhesión química o específica a las estructuras dentales mediante un proceso de intercambio iónico $[9,10,12]$, un coeficiente de variación dimensional térmica muy 
similar al de la pieza dentaria, lo que ayuda a que se mantengan unidos a ella, y la liberación de fluoruros in vitro e in vivo que les confiere un efecto cariostático $[10,11,13]$. En sus inicios, los ionómeros vítreos convencionales presentaban el inconveniente de una tenacidad a la fractura relativamente baja y una velocidad de desgaste oclusal elevada, en comparación con la amalgama [4,14,15]. Se han realizado modificaciones en la composición química de los mismos con el fin de contrarrestar estas desventajas y hoy en día estos ionómeros vítreos modernos son promisorios, no sólo como restauraciones provisorias de larga duración sino también como restauraciones permanentes en dientes posteriores [1,2,4,5].

Sin embargo, a pesar del desarrollo y las características positivas de estos materiales, un factor que influye en el rendimiento clínico de las restauraciones dentales es su resistencia al deterioro. En la cavidad oral estos materiales están sometidos a una serie de condiciones que pueden causar cambios en las propiedades estéticas, físicas, mecánicas y químicas.

Uno de los factores que pueden afectar la calidad de las restauraciones está relacionado con la dieta, el consumo de ciertos alimentos y bebidas como café, té, refrescos, bebidas alcohólicas, incluso agua fluorada puede alterar las características del material original [16-20]. El efecto de estas bebidas en el color y la microdureza de los materiales de restauración varía en función de las características intrínsecas de dicho material, tales como su composición química $[16,18,20]$. Se ha encontrado que la alteración química lenta de las restauraciones dentales puede ir acompañada por la liberación de elementos quimicos, y estos pueden producir ciertos efectos biológicos [21,22]. Por otro lado, los espacios pequeños entre la restauración y la estructura dental pueden llevar a la colonización por bacterias y al desarrollo de caries secundaria, una de las principales causas de fracaso de la restauración [2].

En general, los daños superficiales, la liberación y la absorción de iones inorgánicos y la acción bacteriana alteran las propiedades de los ionómeros de vidrio y limitan la longevidad de una restauración dental. Estos procesos requieren el estudio de la química y la física de superficies, que son fenómenos diferentes de los del volumen interno, y su estudio por consiguiente, requiere de métodos específicos [21-23]. La técnica de PIXE es adecuada para acercarse a este tipo de problemas debido a su capacidad para el análisis de elementos traza en una capa fina de material [21-25]. En este trabajo se estudia el efecto de bebidas de consumo habitual en la composición elemental de un ionómero comercial utilizando dicha técnica.

\section{MATERIALES Y MÉTODOS}

En este trabajo se estudió el comportamiento del ionómero comercial Ketac Molar Easymix. Para la preparación de las muestras se mezcló a temperatura ambiente la cantidad adecuada de polvo y líquido orgánico, de acuerdo a las instrucciones del fabricante. La pasta obtenida se llevó a moldes metálicos que permitieron obtener muestras cilíndricas de $5 \mathrm{~mm}$ de diámetro por $2,5 \mathrm{~mm}$ de altura. Los moldes fueron previamente lubricados con un lubricante en aerosol no reactivo (compuesto principalmente por hidrocarburos), que no afecta a las superficies planas del ionómero analizadas.

Una vez dentro del molde, cada muestra se presionó con un émbolo para eliminar las burbujas de aire, se cubrieron con placas de vidrio y se estacionaron durante dos horas en estufa de cultivo a $37^{\circ} \mathrm{C}$.

\subsection{Tratamiento de las muestras}

Transcurridas dos horas, las muestras se removieron de los moldes y se sumergieron inmediatamente en 50 $\mathrm{ml}$ de infusiones de consumo habitual: té negro, café, mate y agua mineral. Cada bebida se preparó de acuerdo a las instrucciones del fabricante, con agua mineral. Se enfrió hasta $36^{\circ} \mathrm{C}$ y se determinó su pH con un pHmetro Altronix Ezdo-PC. Las muestras se almacenaron durante 0,9, 3, 7, 20 y 33 días a $36^{\circ} \mathrm{C}$ en cada medio. Periódicamente se renovaron dichos medios para evitar su descomposición y mantener constante el pH. En la Tabla 1 se indica el pH de las bebidas utilizadas, previo a la inmersión de las muestras.

Tabla 1: pH de las bebidas utilizadas como medio de almacenamiento del ionómero comercial.

\begin{tabular}{l|l}
\hline BEBIDA & PH \\
\hline Café & 5,5 \\
\hline Té negro & 5,76 \\
\hline Mate & 5,91 \\
\hline Agua Mineral & 8,13 \\
\hline
\end{tabular}


Ertas et al. reportaron que entre los bebedores de café, el tiempo de consumo promedio de una taza de café (300 ml) es de 15 minutos, y que la cantidad promedio de consumo es de 3,2 tazas por día [26]. Esto significa que el tiempo de contacto entre el ionómero y la infusión, o tiempo de almacenamiento ( $\mathrm{t}_{\mathrm{a}}$ ), es de 15 minutos por taza consumida. En un total de 3,2 tazas consumidas por día, $\mathrm{t}_{\mathrm{a}}$ sería de 48 minutos (0,8 horas). Por lo tanto, un tiempo de almacenamiento de 24 horas simula aproximadamente un mes de consumo de café.

Aplicando este concepto a las cuatro infusiones estudiadas en el presente trabajo, un tiempo de almacenamiento de 21 horas (0,9 días) equivale aproximadamente a 26 días de consumo de cada infusión. El tiempo equivalente de consumo de todas las infusiones, en este experimento, estaría en el rango de 26 días a 33 meses (Tabla 2).

Tabla 2: Tiempo equivalente de consumo de cada bebida de acuerdo al tiempo de almacenamiento de las pastillas en cada medio.

\begin{tabular}{l|l}
\hline TIEMPO DE ALMACENAMIENTO [DÍAS] & TIEMPO EQUIVALENTE DE CONSUMO [DÍAS] \\
\hline 0,9 & 26 \\
\hline 7 & 210 \\
\hline 20 & 600 \\
\hline 33 & 990 \\
\hline
\end{tabular}

Si bien el agua mineral es una bebida que se consume en menor tiempo y en mayor cantidad por día, en este trabajo la consideraremos como referencia, y en la misma proporción que las infusiones, ya que fue el medio usado para preparar dichas infusiones.

\subsection{Mediciones PIXE}

Las mediciones PIXE se realizaron con un haz de protones de $2 \mathrm{MeV}$ en un acelerador Tandem 1.7MV (Centro Atómico Bariloche, Río Negro, Argentina).

Se retiraron cinco muestras de cada medio de almacenamiento, se lavaron con agua destilada y se dejaron secar. Paralelamente se prepararon pastillas del ionómero Ketac Molar Easymix, y mediante prensado se obtuvieron pastillas del café, té negro y mate comerciales, para poder conocer la composición elemental del ionómero virgen, y de las infusiones utilizadas como medio de almacenamiento. La composición del agua mineral fue proporcionada por el fabricante.

Para realizar las mediciones, las muestras se fijaron en soportes de aluminio del equipo de medición, y se mantuvieron en vacío durante 24 hs. Un haz de protones de $2 \mathrm{MeV}$ incidió perpendicularmente sobre la superficie de la muestra. Los rayos X emitidos fueron colectados por un detector Sirius SD (detector de silicio refrigerado por efecto Peltier), el análisis espectral se realizó con el software GUPIX [27].

\subsection{Cálculos de transporte de iones en la materia (TRIM)}

Con el fin de asignar una profundidad de capa a la composición química medida a través de PIXE, se usó el software SRIM 2013.00 [28] que permite el cálculo de las características del transporte de protones en el material estudiado.

Se simularon las trayectorias de 20000 protones, con una energía cinética de $2 \mathrm{MeV}$ cada uno, impactando perpendicularmente sobre la superficie de una capa de material con la composición del ionómero vítreo utilizado en este trabajo y 100 micrones de espesor. La pérdida de energía de los protones se debió principalmente a procesos de ionización, en los que se gasta el 99,91\% de su energía. Los valores obtenidos para las proyecciones longitudinal, lateral y radial del haz de protones fueron $60 \mu \mathrm{m}$ (straggling $2 \mu \mathrm{m}), 2.7 \mu \mathrm{m}$ (straggling $3.8 \mu \mathrm{m}$ ) y $4.2 \mu \mathrm{m}$ (straggling $3.5 \mu \mathrm{m}$ ), respectivamente. Esto indica que las mediciones de composición química realizadas en este trabajo corresponden a lo sumo a una capa de 60 micrones de espesor. 


\section{RESULTADOS Y DISCUSIÓN}

3.1 Composición elemental del IV comercial y los ingredientes utilizados para la preparación de las bebidas

La Figura 1 muestra el espectro PIXE obtenido para el ionómero comercial virgen.

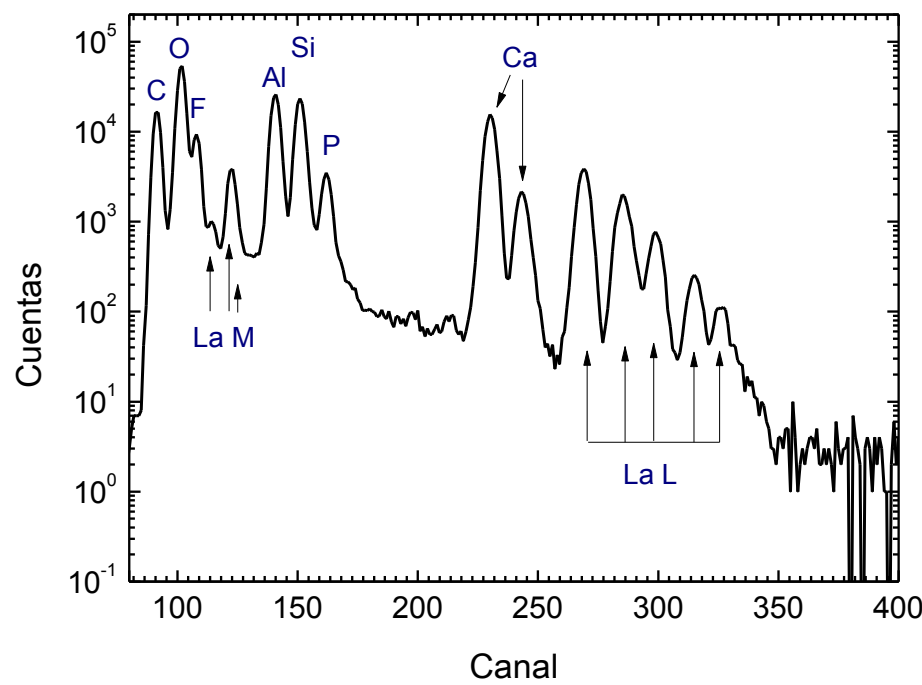

Figura 1: Espectro PIXE del ionómero comercial virgen.

La amplitud de los picos está relacionada cualitativamente con la concentración elemental de las muestras. Los elementos detectados incluyen principalmente C, O, F, Na, Al, Si, P, Ca y La, y sus respectivas concentraciones se presentan en la Tabla 3.

Tabla 3: Composición elemental original de la superficie del ionómero de vidrio (IV) comercial detectada por PIXE.

\begin{tabular}{l|l|l}
\hline ELEMENTOS DETECTADOS & CONCENTRACIÓN [\% P/P] & ERROR [\%] \\
\hline $\mathrm{C}$ & 22,1 & 0,5 \\
\hline $\mathrm{O}$ & 35,0 & 0,2 \\
\hline $\mathrm{F}$ & 5,7 & 1,2 \\
\hline $\mathrm{Na}$ & 1,4 & 1,2 \\
\hline $\mathrm{Mg}$ & 0,04 & 27,1 \\
\hline $\mathrm{Al}$ & 8,1 & 1,3 \\
\hline $\mathrm{Si}$ & 7,7 & 0,3 \\
\hline $\mathrm{P}$ & 1,2 & 1,1 \\
\hline $\mathrm{Ca}$ & 6,6 & 1,0 \\
\hline $\mathrm{Fe}$ & 0,01 & 44,9 \\
\hline $\mathrm{La}$ & 12,1 & 0,7 \\
\hline
\end{tabular}

La composición elemental de los ingredientes utilizados para la preparación de bebidas (café, té y mate) se muestra en la Figura 2. 


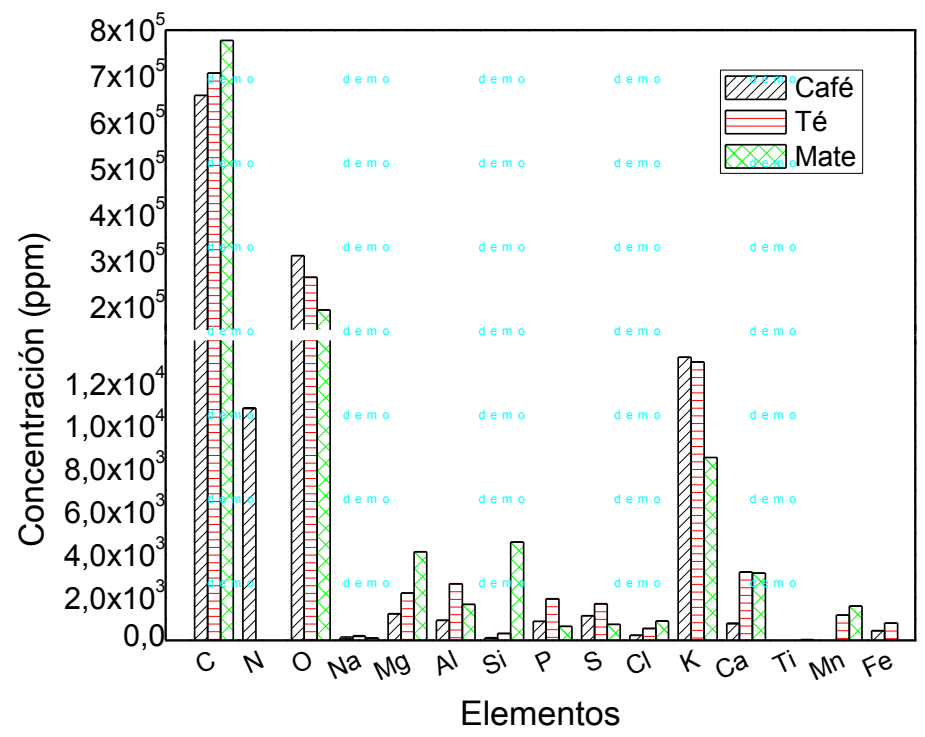

Figura 2: Composición elemental de las muestras puras de café, té y mate detectada por PIXE.

Un grupo de elementos que está presente en los ingredientes de preparación no se encuentra en el ionómero virgen, tales como nitrógeno, azufre, cloro, potasio, titanio y manganeso (Fig. 2, Tabla 4).

Tabla 4: Composición elemental de las muestras puras de café, té y mate utilizadas para preparar las infusiones detectada por PIXE.

\begin{tabular}{|c|c|c|c|c|c|c|}
\hline \multirow[t]{2}{*}{ ELEMENTOS } & \multicolumn{2}{|l|}{ CAFÉ } & \multicolumn{2}{|l|}{ TÉ } & \multicolumn{2}{|l|}{ MATE } \\
\hline & $\begin{array}{l}\text { CONCENTRACIÓN } \\
\text { [PPM] }\end{array}$ & $\begin{array}{l}\text { ERROR } \\
\text { [\%] }\end{array}$ & $\begin{array}{l}\text { CONCENTRACIÓN } \\
\text { [PPM] }\end{array}$ & $\begin{array}{l}\text { ERROR } \\
\text { [\%] }\end{array}$ & $\begin{array}{l}\text { CONCENTRACIÓN } \\
\text { [PPM] }\end{array}$ & $\begin{array}{l}\text { ERROR } \\
\text { [\%] }\end{array}$ \\
\hline $\mathrm{C}$ & 658565 & 0,2 & 707177 & 0,2 & 777674 & 0,1 \\
\hline $\mathrm{N}$ & 10829 & 36 & 264145 & 0,4 & 193433 & 0,2 \\
\hline $\mathrm{O}$ & 311018 & 0,4 & 205 & 31 & 103 & 26 \\
\hline $\mathrm{Na}$ & 105 & 72 & 2210 & 3 & 4127 & 0,8 \\
\hline $\mathrm{Mg}$ & 1236 & 5 & 2644 & 2 & 1681 & 1 \\
\hline $\mathrm{Al}$ & 936 & 5 & 319 & 10 & 4589 & 0,6 \\
\hline $\mathrm{Si}$ & 116 & 28 & 1936 & 2 & 658 & 2 \\
\hline $\mathrm{P}$ & 888 & 4 & 1712 & 2 & 658 & 2 \\
\hline$S$ & 1154 & 3 & 556 & 5 & 747 & 2 \\
\hline $\mathrm{Cl}$ & 238 & 10 & 12987 & 0,8 & 908 & 2 \\
\hline $\mathrm{K}$ & 13201 & 0,8 & 3192 & 6 & 8529 & 0,5 \\
\hline $\mathrm{Ca}$ & 785 & 21 & 3192 & 6 & 3131 & 3 \\
\hline $\mathrm{Ti}$ & - & - & - & - & 31 & 21 \\
\hline Mn & - & - & 1174 & 7 & 1605 & 3 \\
\hline $\mathrm{Fe}$ & 451 & 21 & 801 & 12 & 240 & 13 \\
\hline
\end{tabular}

3.2 Variación de la concentración de los principales elementos del IV comercial por acción de las infusiones

Luego del almacenamiento de las muestras en las infusiones se observó una notable diferencia en la composición elemental de la superficie del ionómero vítreo con respecto a las muestras de partida. Las Figuras 3-7 muestran dicha variación, luego de la inmersión de las pastillas en cada medio. 
En general, se observó una notoria disminución de la concentración de sodio después del almacenamiento del ionómero en todos los medios, siendo este efecto más marcado en café, con una pérdida del $90 \%$ de la concentración tras tan sólo 7 días de almacenamiento, y en menor grado en el agua mineral. El comportamiento del resto de los elementos fue sumamente complejo, y dependió de cada medio de almacenamiento.

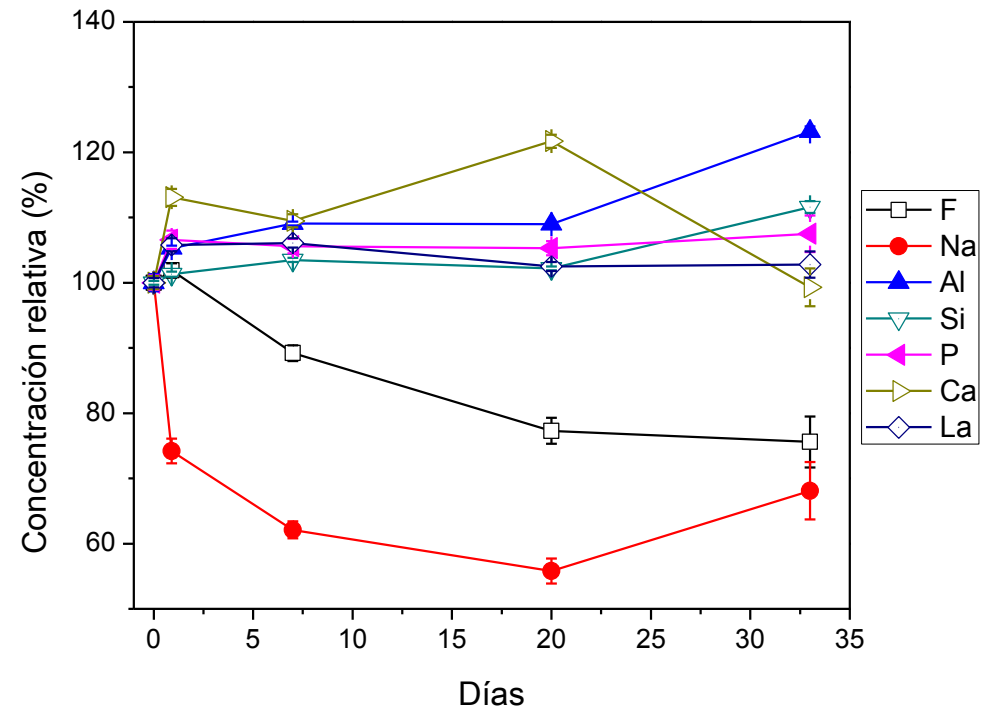

Figura 3: Concentración relativa de los elementos de la superficie del ionómero de vidrio almacenado en agua mineral.

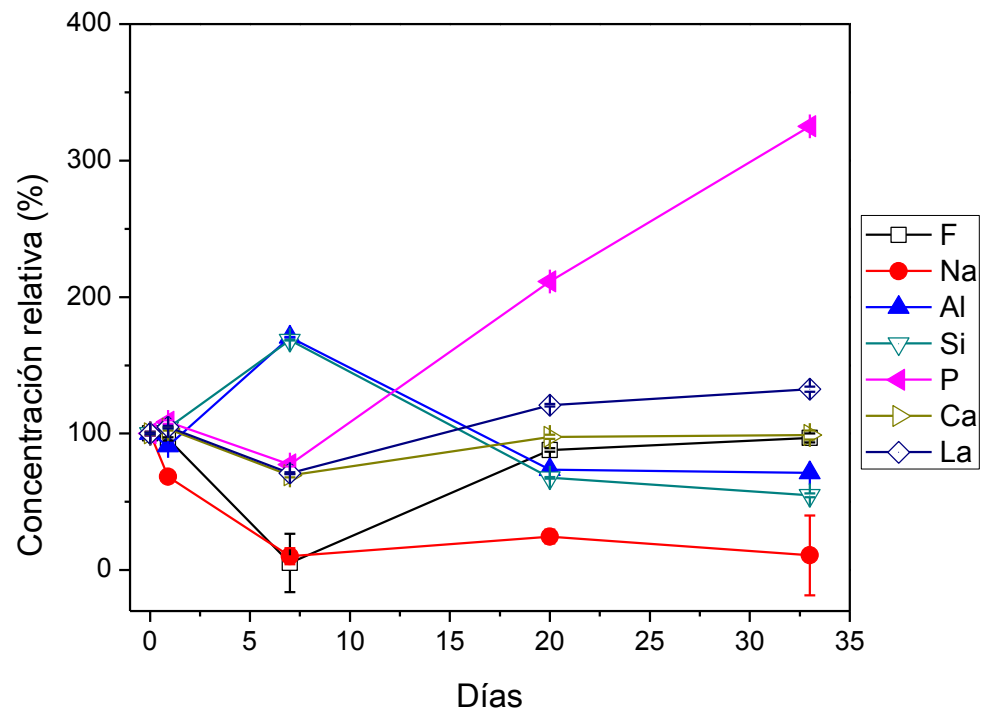

Figura 4: Concentración relativa de los elementos de la superficie del ionómero de vidrio almacenado en café. 


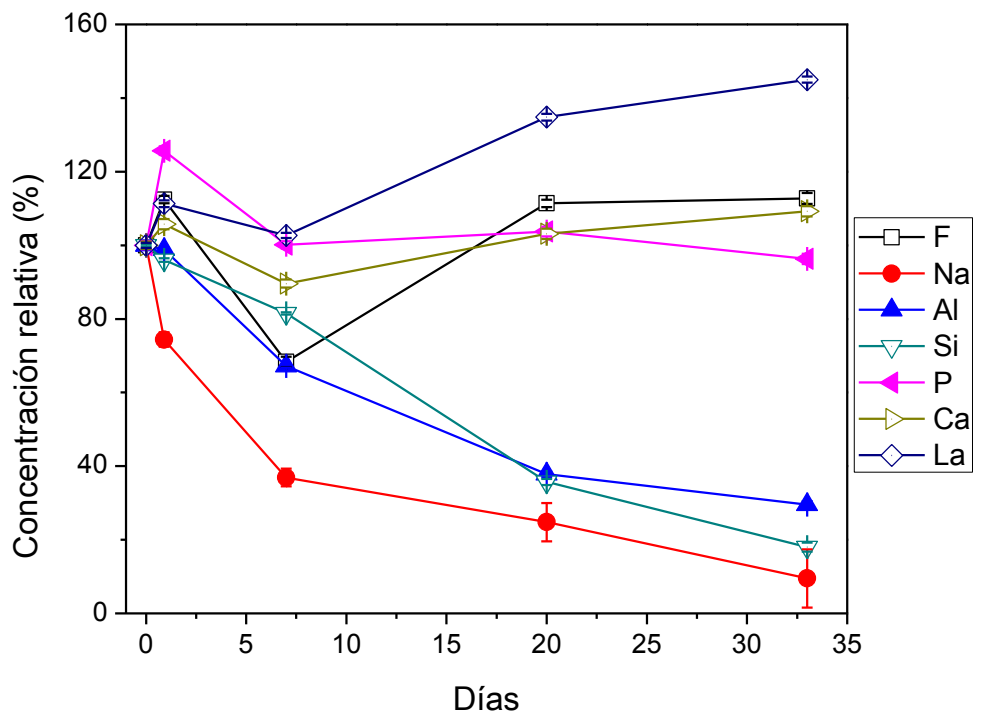

Figura 5: Concentración relativa de los elementos de la superficie del ionómero de vidrio almacenado en té.

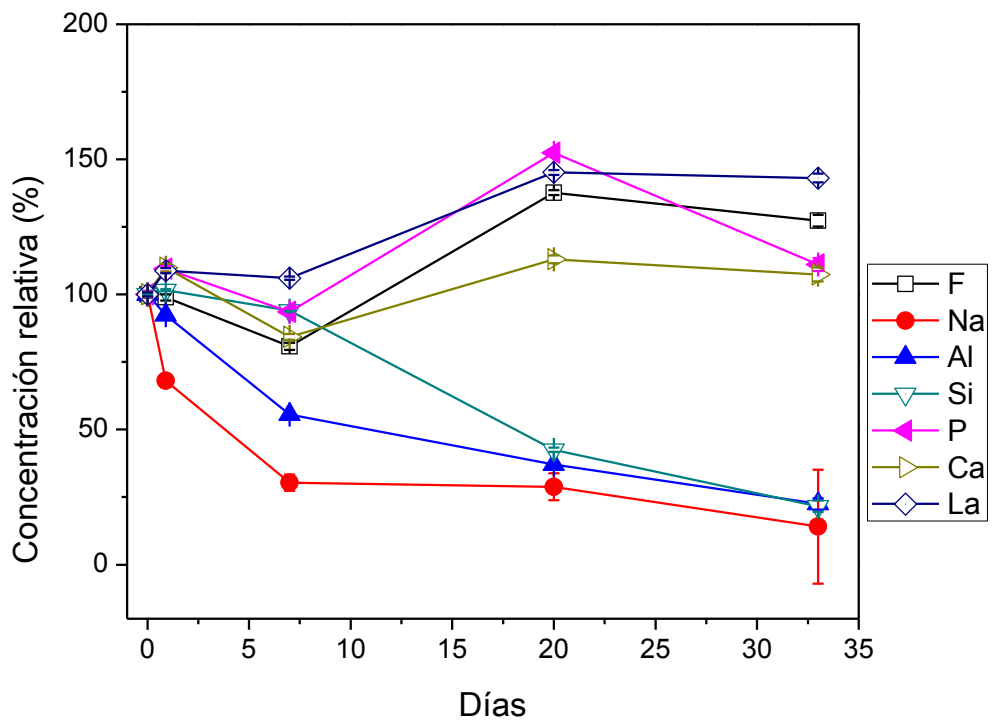

Figura 6: Concentración relativa de los elementos de la superficie del ionómero de vidrio almacenado en mate.

\subsection{Variación de la composición elemental de la superficie del IV en agua mineral}

En agua mineral, la pérdida de sodio fue acompañada por una disminución de F, siguiendo ambos el mismo perfil de concentración (Fig.7). Este efecto fue observado por WILSON et al. [29] quienes estudiaron la liberación de fluoruro y otras especies químicas a partir de un cemento de ionómero de vidrio en agua destilada. Ellos llegaron a la conclusión de que la liberación de fluoruro es controlada por la liberación de sodio a fin de preservar la electroneutralidad del sistema, y que el fluoruro asociado con cationes distintos de sodio parece no estar disponible para su liberación. 


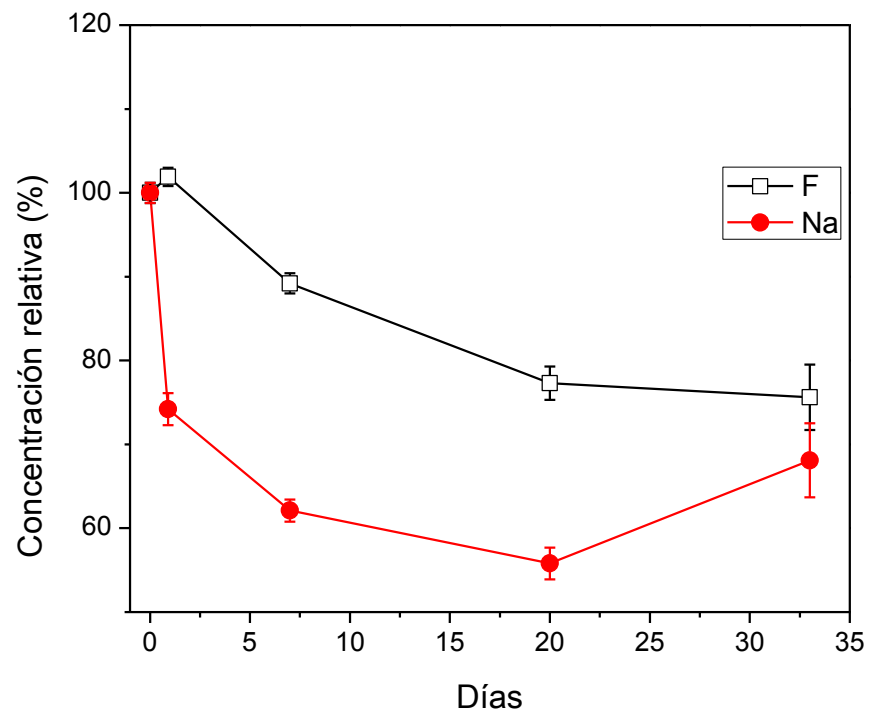

Figura 7: Concentración relativa de F y $\mathrm{Na}$ en la superficie del ionómero de vidrio almacenado en agua.

Durante el experimento en este medio se observó además un leve incremento en la concentración de aluminio, calcio, fósforo y lantano las primeras 20 horas de almacenamiento, siendo dicho incremento de aproximadamente el 15\% para el calcio, y del 5\% para el resto de los elementos. A partir de ahí, el fósforo y el lantano mantuvieron aproximadamente constantes hasta el final del almacenamiento. El calcio presentó incrementos y disminuciones en los distintos tiempos de estudio, alcanzando una ganancia del $22 \%$ a los 20 días de inmersión, para luego decaer a su valor inicial al finalizar el experimento. En esta instancia, el silicio y el aluminio mostraron un incremento en la concentración (12\% y 23\% respectivamente). Estos resultados difieren de lo que se espera para estos elementos, ya que otros autores han reportado que tanto el aluminio, como el silicio y el fósforo se liberan del material en cualquier situación, independientemente del $\mathrm{pH}$, siendo este efecto más marcado en medios ácidos [30-32]. Esto pone de manifiesto el efecto de los iones presentes en el agua mineral, que por un lado disminuyen la velocidad de salida de los iones desde el ionómero hacia el medio circundante, y por otro favorecen la formación de depósitos insolubles sobre la superficie del material que con el tiempo podrían precipitar. El incremento de la concentración de calcio a los veinte días y posterior disminución podría deberse a este efecto.

\subsection{Variación de la composición elemental de la superficie del IV en bebidas ácidas}

En los medios ácidos la variación de la composición elemental fue compleja. El almacenamiento de las muestras en mate y té determinó dos grupos de elementos: Na, Al y Si (Grupo I), La, F y Ca (Grupo II). En el primer grupo se observó una disminución de la concentración hasta el final del experimento, mientras que en el segundo grupo se detectó una ganancia en su concentración. El punto de inflexión se observó a los siete días de almacenamiento, a partir de los cuales cada grupo presentó un comportamiento diferente. Dentro del Grupo II fue posible localizar un segundo punto de inflexión a los 20 días de inmersión, más allá del cual sólo se observó un leve aumento o descenso de la concentración. Algunos elementos como P, Ca, F y La presentaron un pequeño aumento en su concentración después de 21 hs de inmersión, siendo este efecto más marcado en el caso del P, después de la inmersión en té (Figuras 5 y 6).

El almacenamiento del ionómero en café no permitió separar grupos de elementos, pero los puntos de inflexión fueron los mismos. Los cambios más notorios se observaron a los siete días de almacenamiento en los elementos $\mathrm{Al}$ y Si, que a diferencia del comportamiento de las muestras estacionadas en mate y té sufrieron un incremento en su concentración del $60 \%$ con respecto a su valor inicial (Figuras 8). 


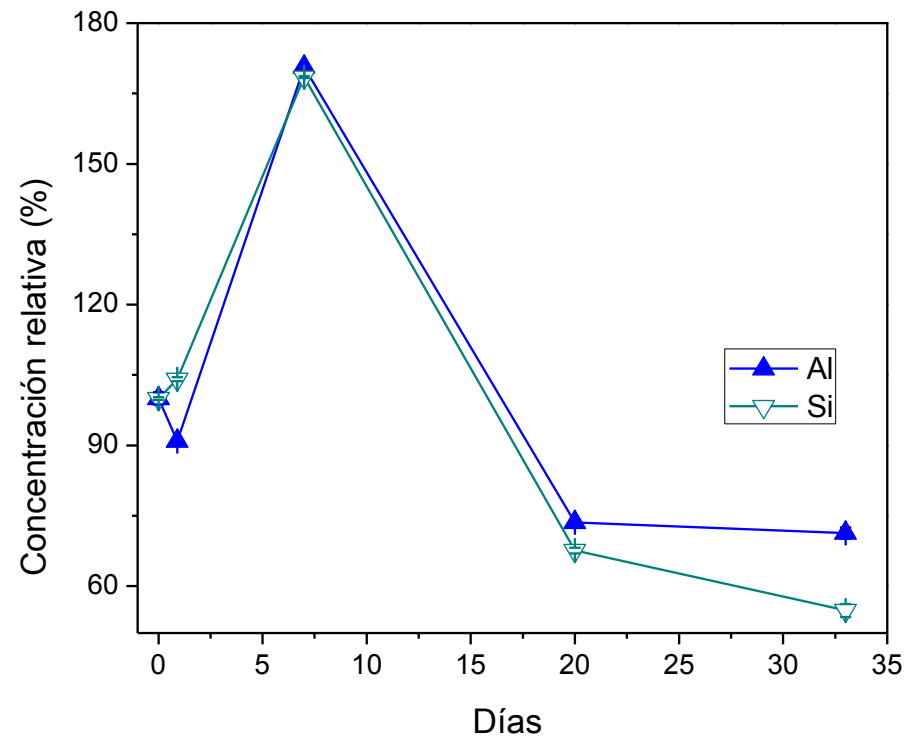

Figura 8: Concentración relativa de Al y Si en la superficie del ionómero de vidrio almacenado en café.

Las Figuras 9 y 10 muestran la variación de la concentración de aluminio y silicio en todos los medios. En mate y té dicha variación fue gradual, con una pérdida de aproximadamente el $80 \%$ a los 33 días de almacenamiento. En agua mineral la concentración de estos elementos se mantuvo aproximadamente constante en todo el experimento, con un leve aumento hacia el final.

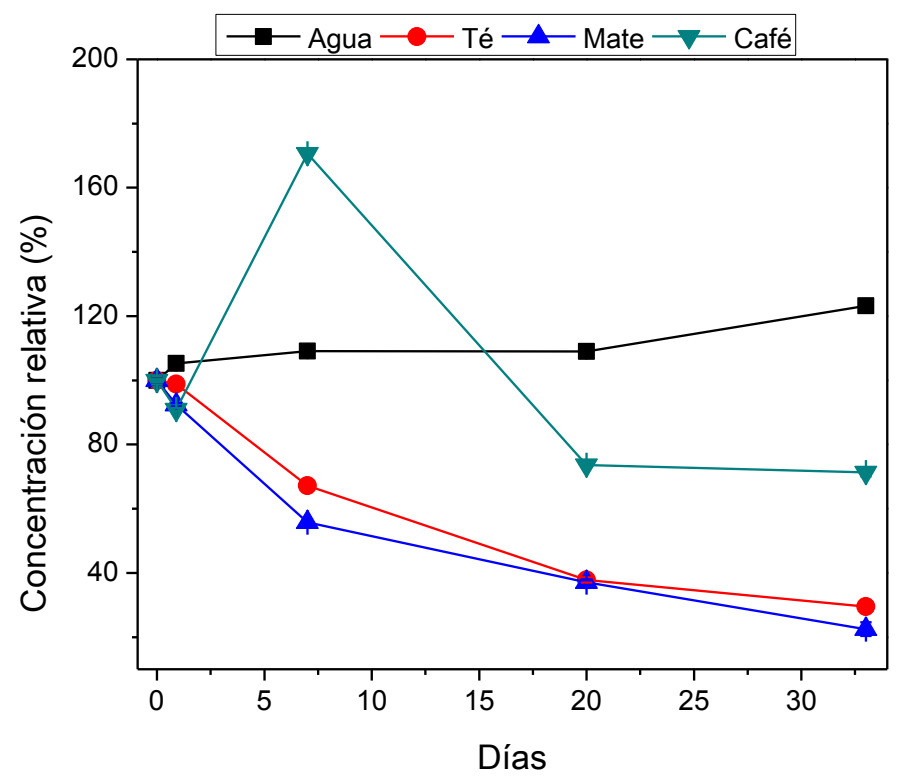

Figura 9: Concentración relativa $\mathrm{Al}$ en la superficie del ionómero de vidrio almacenado en todos los medios. 


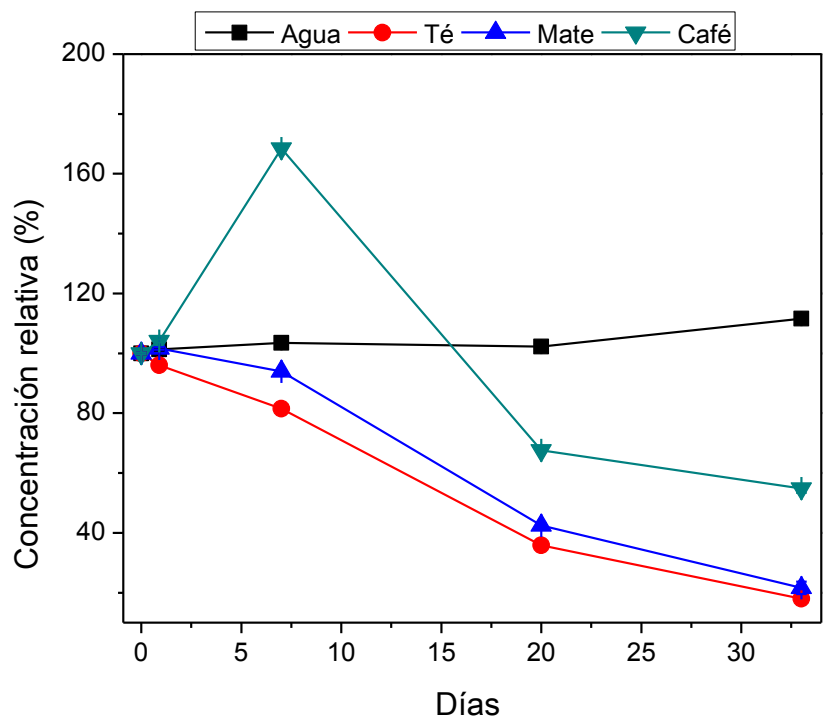

Figura 10: Concentración relativa de Si en la superficie del ionómero de vidrio almacenado en todos los medios.

Si bien el perfil de concentración de los elementos fue diferente en las distintas bebidas de almacenamiento, en todos ellos la relación Al:Si fue cercana la unidad a lo largo del experimento. Esto sugiere que dentro de las primeras cuatro semanas pudo haber existido un conjunto de compuestos químicos formados a partir de dichos elementos, y que son éstos compuestos los que sufren los cambios durante el tiempo de almacenamiento. Como se mencionó anteriormente, en el caso de las muestras almacenadas en café durante siete días se detectó un aumento de la concentración de aluminio y silicio. Podría pensarse que ese aumento de concentración proviene de la interacción de estos elementos con los iones del medio circundante, sin embargo de acuerdo al análisis PIXE de las muestras de referencia, el café presenta una menor concentración de Al y Si, comparada con las muestras de té y mate (Figura 2 y Tabla 4), por lo que se puede inferir que la mayor concentración de dichos elementos en la superficie no provienen de la interacción de la misma con los iones circundantes, sino de la mayor liberación de compuestos de aluminio y silicio desde el interior, los cuales inicialmente se acumulan, y luego se disuelven con el tiempo de almacenamiento. Esto sugiere que el café tiene mayor poder de penetración que las otras bebidas, favoreciendo la salida selectiva de algunos elementos.

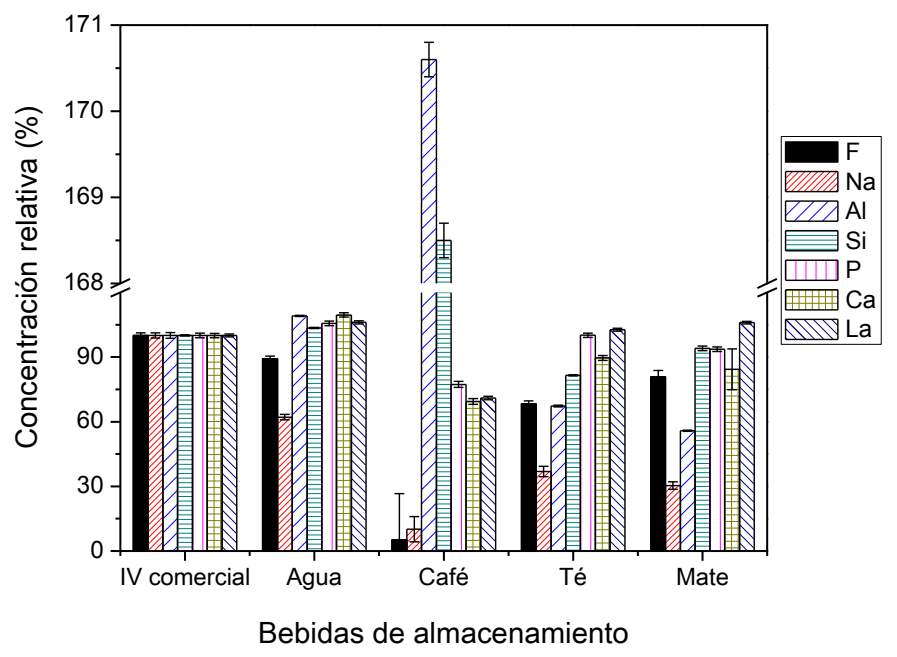

Figura 11: Composición química superficial del IV, luego de una semana de permanencia en los distintos medios, respecto del IV comercial virgen, con una concentración relativa del 100\% como se observa en el lado izquierdo de la Figura. 
La Figura 11 permite comparar y apreciar mas fácilmente los cambios en la concentración elemental de las muestras inmersas una semana en las distintas bebidas, respecto del ionómero de vidrio comercial virgen, sin tratamiento alguno.

Además de los elementos mencionadas anteriormente, el F fue uno de los que mayor variación sufrió en su concentración después de permanecer siete días en café, siendo su pérdida de casi el 100\%, frente al mate y té que presentaron una disminución del $20 \%$ y 30\%, respectivamente (Figura 11). Sin embargo, las muestras estacionadas en las tres bebidas mostraron una similitud en el perfil de concentración de flúor con los de calcio y lantano (Figuras 12 -14), principalmente con este último.

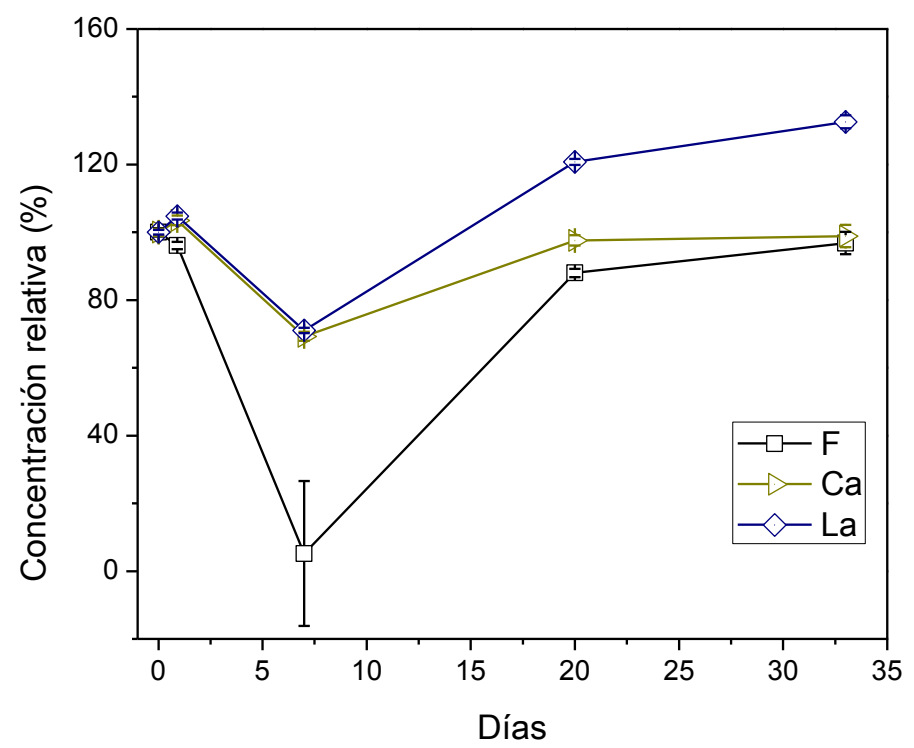

Figura 12: Concentración relativa de F y La en la superficie del ionómero de vidrio almacenado en café.

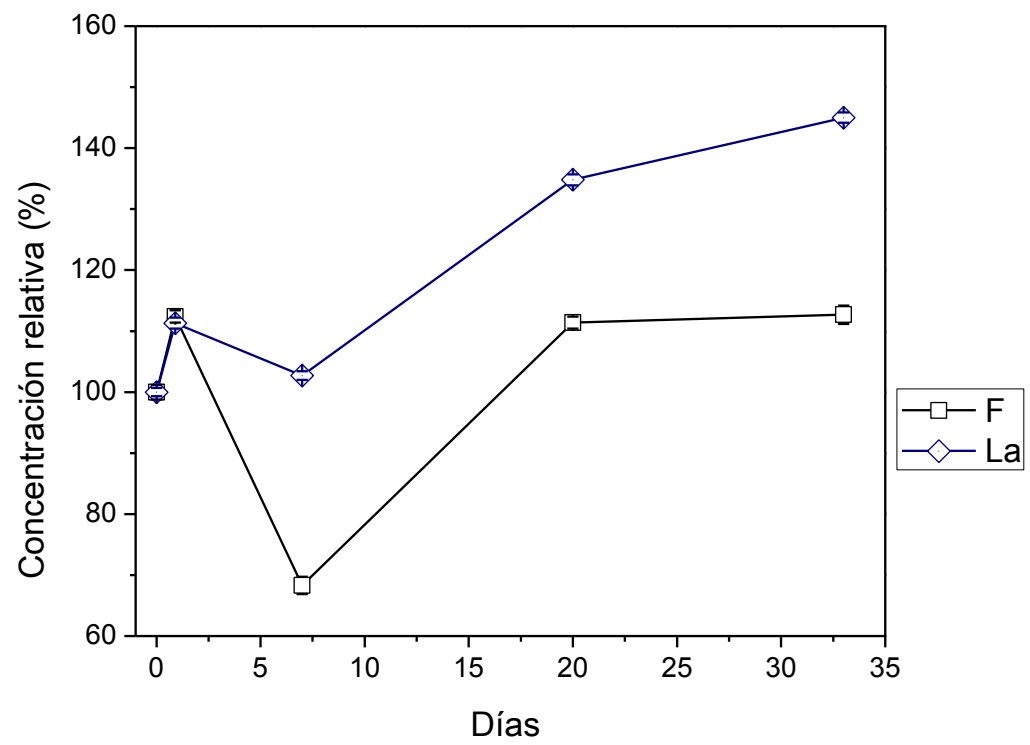

Figura 13: Concentración relativa de F y La en la superficie del ionómero de vidrio almacenado en té. 


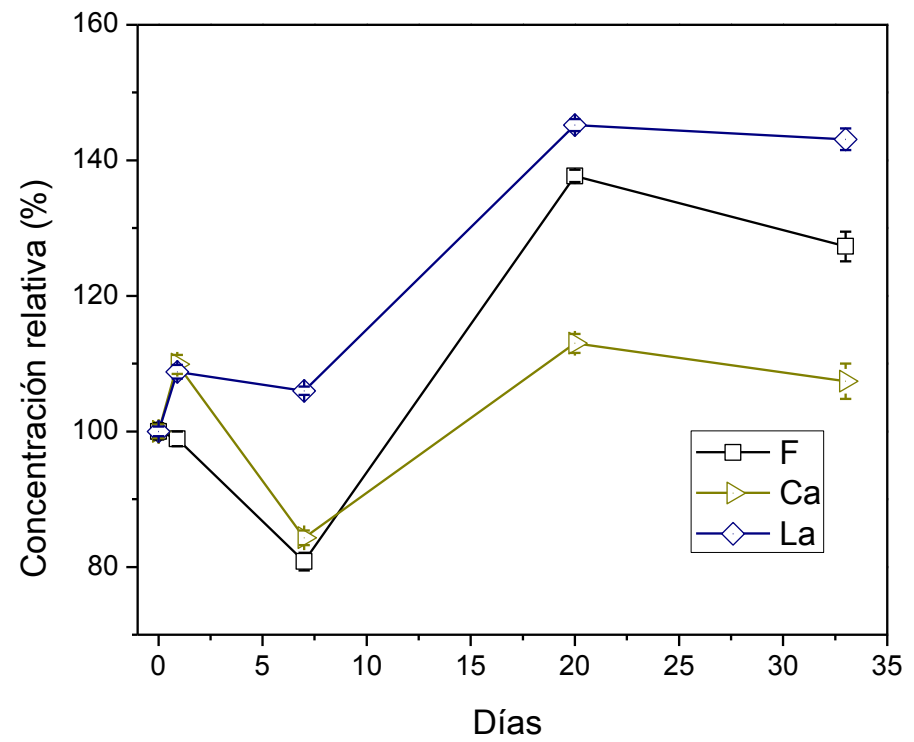

Figura 14: Concentración relativa de F, Ca y La en la superficie del ionómero de vidrio almacenado en mate.

Esto sugiere que el almacenamiento en medio ácido, favorece la liberación del flúor formando compuestos de calcio y lantano. Existe alguna evidencia de que el aluminio se puede asociar con fluoruro, con el cual, es sabido, que se compleja fuertemente [33]. WILSON [7] postuló la presencia de especies complejas del tipo $\mathrm{AlF}^{2+}$ y $\mathrm{AlF}_{2}{ }^{+}$entre los iones lixiviados de los ionómeros de vidrio. No hay evidencia experimental directa para esto. Sin embargo, los estudios han demostrado que en condiciones ácidas, una mayor proporción del fluoruro liberado es complejado [7,33,34]. En este trabajo, los perfiles de concentración no mostraron ninguna correlación entre el flúor y aluminio. Por otro lado, se observó un comportamiento caótico de fósforo. No fue posible encontrar una relación entre dicho elemento y algún otro en particular.

\subsection{Adsorción de elementos desde las infusiones}

Además de la variación de la concentración de los principales elementos constituyentes del ionómero comercial, se detectó la presencia de nuevos elementos como el potasio y manganeso (Figura 15 y 16), y el incremento de la concentración de magnesio y hierro, que sólo se habían detectado como trazas al principio del experimento.

En la Figura 15 se observa la variación de la concentración de potasio. Después del almacenamiento durante siete días en mate y té la concentración fue de 5547 y 5534 ppm respectivamente, y se mantuvo aproximadamente constante hasta el final del experimento. En las pastillas almacenadas el mismo tiempo en café, se detectó una concentración levemente inferior (4957 ppm), pero que a diferencia de las anteriores se incrementó hasta el final del experimento, alcanzando un valor de aproximadamente $1530 \mathrm{ppm}$. En agua mineral sólo se detectaron trazas a los siete días (76 ppm). HADLEY et al. [35] reportaron que el potasio podía ser absorbido por un cemento de ionómero vítreo después de su inmersión en soluciones de KF, y que esta absorción es función de la erosión de la matriz del compuesto. Ellos propusieron que los iones K no podían penetrar en las partículas de vidrio sin disolver, ubicándose en consecuencia en la matriz del material. El contacto de la solución de KF con el ionómero producía la disolución de dicha matriz, por lo cual el K sólo se hacía evidente a una profundidad donde la erosión de la matriz ya no era un factor. Este efecto se observó en las pastillas almacenadas en café. Como se mencionó anteriormente, esta bebida mostró mayor poder de penetración en el material que el resto de las bebidas, es decir mayor poder de disolución de la matriz del material, y ese efecto se acentúa con el tiempo de almacenamiento. Por esta razón se detectó mayor concentración de $\mathrm{K}$ después de los 33 días de inmersión. 


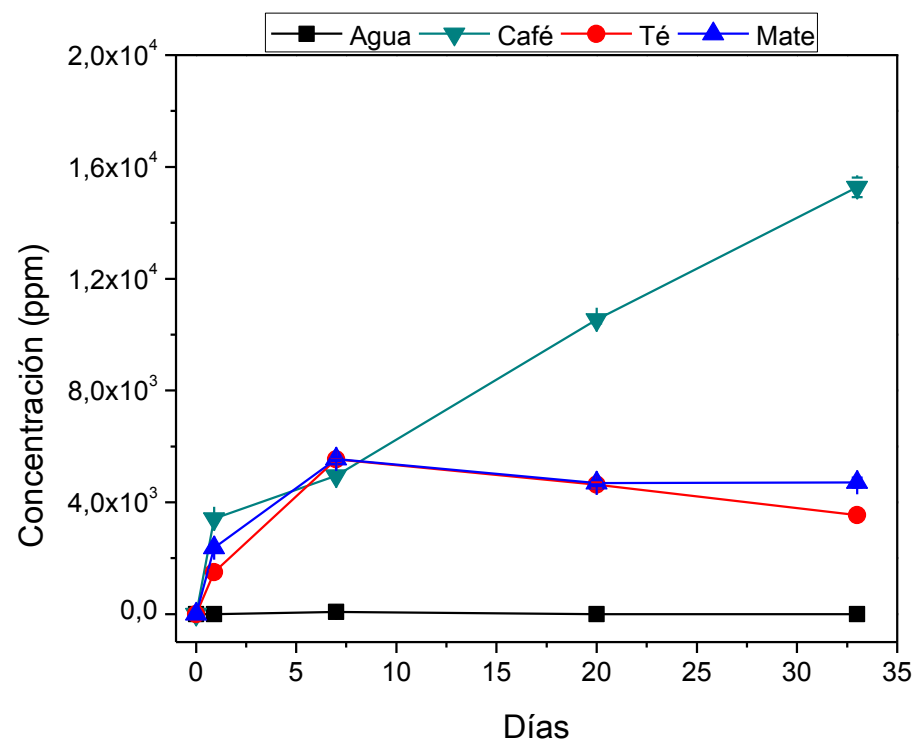

Figura 15: Concentración de $\mathrm{K}$ en la superficie del ionómero de vidrio almacenado en todos los medios.

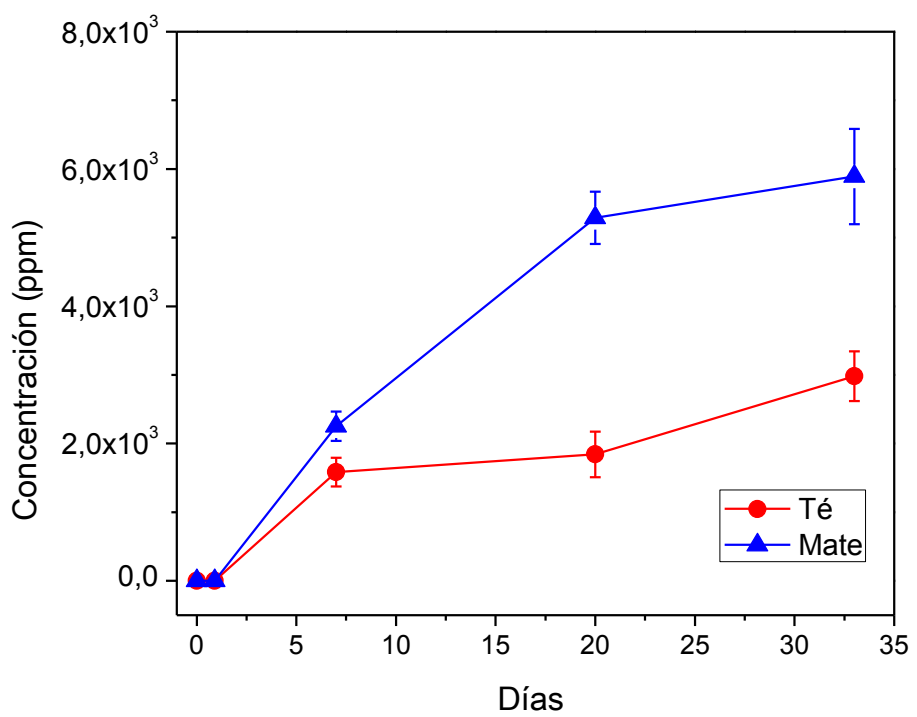

Figura 16: Concentración de Mn en la superficie del ionómero de vidrio almacenado en té y mate.

En el caso del manganeso, su aparición se observó en las pastillas almacenadas en mate y té, ya que sólo estas dos infusiones contenían dicho elemento (Figura 2, Tabla 4). Como se observa en la Figura 16, en mate se produjo un incremento continuo hasta los 33 días de almacenamiento, alcanzando un valor de 6000 ppm, mientras que en té, se observó un aumento de 1584 ppm a los siete días, a partir del cual se observó y muy poca variación durante 13 días más de inmersión (1840 ppm). Al finalizar el estudio, se detectó un incremento del $62 \%$ con respecto al valor anterior, llegando a aproximadamente 3000 ppm, la mitad de la concentración alcanzada por las muestras almacenadas en mate. Esta diferencia es consistente con la mayor concentración de manganeso presente en el mate puro.

Por su parte, el hierro y el magnesio que se encontraban en el ionómero de partida en forma de trazas prácticamente (Figura 2, Tabla 3), sufrieron cambios después del almacenamiento en las bebidas. Como se observa en la Figura 17, se notó un notable incremento en la concentración de hierro después de siete días de inmersión en café. 


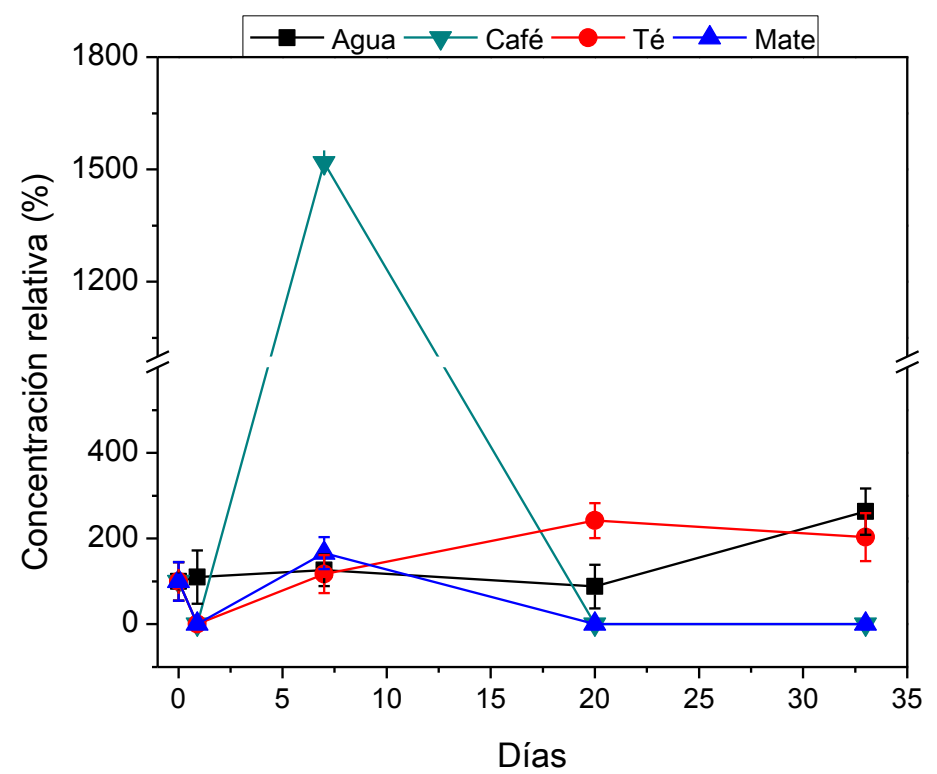

Figura 17: Concentración relativa de Fe en la superficie del ionómero de vidrio almacenado en todos los medios.

No se observan diferencias significativas en las concentraciones de este elemento en las muestras puras de mate, té y café (Tabla 4), razón por la cual este resultado puede atribuirse como en casos anteriores, al mayor poder de penetración de esta bebida, facilitando la salida de elementos de zonas más profundas del material, los cuales se acumulan en la superficie. Sin embargo, este argumento no justifica la variación de la concentración de magnesio, ya que las pastillas retiradas de mate y té, presentaron un incremento en la concentración a lo largo del experimento, superior al observado en las pastillas estacionadas café (Figura 18).

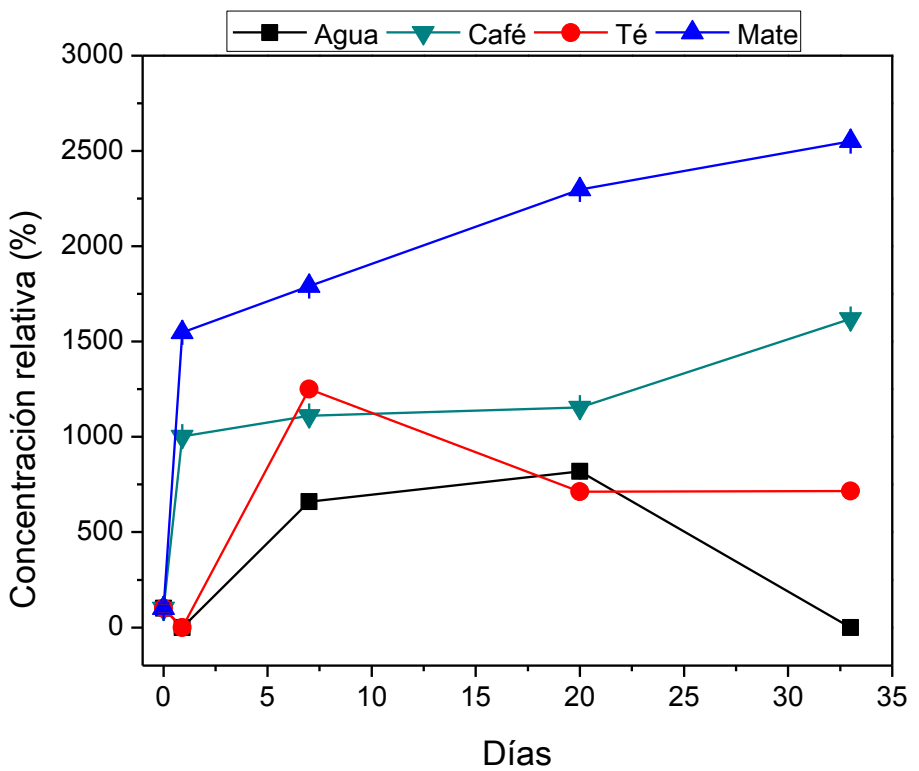

Figura 18: Concentración relativa de $\mathrm{Mg}$ en la superficie del ionómero de vidrio almacenado en todos los medios.

En este caso, el análisis PIXE de las muestras puras de mate, té y café sí presentó una diferencia en la concentración de magnesio, siendo superior en mate (mate $>$ té $>$ café) (Tabla ). Esto sugiere que la absorción de este elemento desde el líquido circundante predomina sobre el efecto de erosión del material.

En general, la absorción de cationes de valencia distinta de uno ha sido escasamente reportada. El me- 
canismo de absorción de estos iones en los IV merece ser estudiado.

\section{CONCLUSIONES}

En este trabajo se estudió el efecto de bebidas de consumo diario sobre la composición elemental de la superficie de un ionómero comercial, usando la técnica de Emisión de Rayos X inducida por Protones (PIXE).

La variación de la composición elemental superficial es sumamente compleja y es función tanto del pH de la infusión, como de la interacción de la superficie del IV con los iones que constituyen dicha infusión. Los detalles de los resultados encontrados se mencionan en la sección 3. Sin embargo, es posible concluir lo siguiente:

$>$ Se encontró que a largos tiempos de tratamiento, en todos los medios excepto el agua mineral, se pierde aluminio, silicio y sodio del ionómero de vidrio, lo que representa la disolución parcial de un aluminosilicato sódico. El café presentó mayor poder de disolución que el resto de las bebidas.

$>$ En agua mineral el $\mathrm{F}$ se libera asociado con Na, mientras que en los medios ácidos (café, mate y té) se libera asociado con otros elementos como Ca y La.

$>\mathrm{El}$ contacto del material con las infusiones permitió la incorporación de nuevos elementos como $\mathrm{K}$ y Mn, y el incremento en la concentración de los elementos Fe y Mg que sólo se habían detectado como trazas en el ionómero de partida. Sin embargo el mecanismo de incorporación de iones de valencia $>1$ no está claro, y debe ser investigado.

$>$ Las variaciones en la composición química superficial son drásticas para muchos elementos integrantes del ionómero de vidrio lo cual confirma que a nivel local las propiedades físicoquímicas del material van cambiando con el tiempo durante el cual cumplen su función restauradora.

$>$ La técnica utilizada mostró efectividad en el estudio de la composición química superficial de un ionómero de vidrio. Un estudio comparativo de distintos ionómeros de vidrio podría proporcionar resultados útiles para el diseño de nuevos ionómeros de vidrio.

\section{AGRADECIMIENTOS}

Este estudio ha sido apoyado por CONICET (Consejo Nacional de Investigaciones Científicas y Técnicas), y CNEA (Comisión Nacional de Energía Atómica).

Los autores agradecen a la Dra. Bernarda Quiroga por su asistencia con las determinaciones de PIXE.

\section{BIBLIOGRAFÍA}

[1] BAIG M.S., FLEMING G.J.P., "Conventional glass-ionomer materials: A review of the developments in glass powder, polyacid liquid and the strategies of reinforcement", Journal of Dentistry, v. 43, n. 8, pp. 897912, Aug. 2015.

[2] ALIREZA M., NIMA R., CHEEA W.W.L., SCHRICKER S.R., "A review of powder modifications in conventional glass ionomer dental cements", Journal of Materials Chemistry, v. 21, n. 5, pp. 1319-1328, Feb. 2011.

[3] WILSON A.D., KENT B.E., "The glass ionomer cement, a new translucent dental filling material”, Journal of Applied Chemistry Biotechnology, v. 21, n. 11, pp. 313, Nov. 1971.

[4] FRIEDL K., HILLER K.A., FRIEDL K.H., "Clinical performance of a new glass ionomer based restoration system: A retrospective cohort study", Dental Materials, v. 27, n. 10, pp. 1031-1037, Oct. 2011.

[5] DAVIDSON C.L., "Advances in glass-ionomer cements", Journal of Applied Oral Science, vol. 14, pp. 3-9, 2006.

[6] McLEAN J.W., WILSON A.D., "The clinical development of the glass ionomer cements. I. Formulations and properties", Australian Dental Journal, v. 22, n. 1, pp. 31-36, Feb. 1977.

[7] WILSON A.D., "The chemistry of dental cements", Chemical Society Reviews, vol. 7, n. 2, pp. 265-296, 1978.

[8] WASSON E.A., NICHOLSON J.W., "New aspects of the setting of glass-ionomer cements", Journal of Dental Research, v. 72, n. 2, pp. 481-483, Feb. 1993. 
[9] ANUSAVICE K.J., PHILLIPS. Ciencia de los materiales dentales, 11 ma Edición, Elsevier, España, 2004.

[10] MACCI R.L., Materiales Dentales, 4ta Edición, Editorial Médica Panamericana, Argentina, 2007.

[11] NAGARAJA UPADHYA P., KISHORE G., "Glass Ionomer Cement - The Different Generations", Trends in Biomaterials and Artificial Organs, vol. 18, n. 2, pp. 158-165, 2005.

[12] LIN A., MCINTYRE N.S., DAVIDSON R.D., "Studies on the Adhesion of Glass ionomer Cements to Dentin”, Journal of Dental Research, vol. 71, n. 11, pp. 1836-1841, Nov. 1992.

[13] WIEGAND A., BUCHALLA W., ATTIN T., "Review on fluoride-releasing restorative materialsfluoride release and uptake characteristics, antibacterial activity and influence on caries formation", Dental Materials, vol. 23, n. 3, pp. 343-362, March 2007.

[14] HICKEL R., MANHART J., GARCIA GODOY F., "Clinical results and new developments of direct posterior restorations", American Journal of Dentistry, v. 13, pp. 41D-54D, Nov. 2000.

[15] MANHART J., CHEN H., HAMM G., HICKEL R., "Buonocore memorial lecture review of the clinical survival of direct and indirect restorations in posterior teeth of the permanent dentition", Operative Dentistry, v. 29, n. 5, pp. 481-508, Sept-Oct. 2004.

[16] AWLIYA W.Y., AL-ALWAN D.J. I, GASHMER E.S., et al., "The effect of commonly used types of coffee on surface microhardness and color stability of resin-based composite restorations", The Saudi Dental Journal, v. 22, n. 4, pp. 177-181, Oct.2010.

[17] MCKENZIE M.A., LINDEN R.W.A., NICHOLSON J.W., "The physical properties of conventional and resin-modified glass cements stored in saliva, proprietary acidic beverages, saline and water", Biomaterials, vol. 24, n. 22, pp. 4063-4069, Oct. 2003.

[18] GAINTANTZOPOULOU M., KAKABOURA A., VOUGIOUKLAKIS G., "Color stability of toothcoloured restorative materials", The European Journal of Prosthodontics and Restorative Dentistry, v. 13, n. 2, pp. 51-56, Jun. 2005.

[19] BINDAL, P., BINDAL, U., DABBAGH, A., et al., "Comparative effects of turmeric, coffee, and chewable tobacco on the color stability of tooth-colored restorative materials", Open Journal of Dentistry and Oral Medicine, vol. 3, n. 3, pp. 59-67, Aug. 2015.

[20] LEWIS, S.M., COLEMAN, N.J., BOOTH, S.E., et al., "Interaction of fluoride complexes derived from glass ionomer cements with hydroxyapatite", Ceramics - Silikáty, v. 57, n. 3, pp. 196-200, May. 2013.

[21] PREOTEASA E.A., CIORTEA C., CONSTANTINESCU B., et al., " Analysis of composites for restorative dentistry by PIXE, XRF and ERDA", Nuclear Instruments and Methods in Physics Research B, vol. 198, n. 1-4, pp. 426-430, Apr. 2002.

[22] PREOTEASA E.A., PREOTEASA E., CIORTEA C., et al., "PIXE and PIGE assessment of in vivo elemental and physical changes of a composite from a dental filling", X-Ray Spectrometry, vol. 38, n. 6, pp. 548-556, Apr. 2009.

[23] PREOTEASA E.A., PREOTEASA E., SUCIU I., Atomic and nuclear surface analysis methods: A novel perspective for the characterization of dental composites (Dental Science, Materials and Technology), Nova Science Publishers Inc, 2012.

[24] SUCI, I., PREOTEASA, E.A., GURBAN, D., "Potential of PIXE for the elemental analysis of calcium hidroxide used in dentistry", Romanian Reports in Physics, v. 58, n. 4, pp. 569-582, Jul. 2006.

[25] FUNATO Y., MATSUDA Y., OKUYAMA K., et al., " A new technique for analyzing trace element uptake by human enamel”, Dental Materials Journal, v. 34, n. 2, pp. 240-245, Feb. 2015.

[26] ERTA E., GÜLER A.U., YÜCEL A., et al., "Color Stability of Resin Composites after Immersion in Different Drinks", Dental Materials Journal, v. 25, n. 2, pp. 371-376, Jun. 2006.

[27] LIMANDRI S., OLIVARES C., RODRIGUEZ L., et al., "PIXE facility at Centro Atómico Bariloche", Nuclear Instruments and Methods in Physics Research B, v. 318, pp. 47-50, Jul. 2014.

[28] J.F. Ziegler, INTERACTIONS OF IONS WITH MATTER, http://www.srim.org/SRIM/SRIMLEGL.htm. Accedido en abril de 2016.

[29] WILSON A.D., GROFFMAN D.M., KUHN A.T., "The release of fluoride and other chemical species from a glass ionomer cement”, Biomaterials, v. 6, n. 6, pp. 431-433, Nov. 1985. 
[30] CZARNECKA, B., LIMANOWSKA-SHAW, H., HATTON, R., et al., "Ion release by endodontic grade glass-ionomer cement". Journal of Materials Science: Materials in Medicine, v. 18, n. 4, pp. 649-652, Apr. 2007.

[31] CZARNECKA, B., LIMANOWSKA-SHAW, H., NICHOLSON, J.W., "Buffering and ion release by a glass ionomer cement under near neutral and acidic conditions", Biomaterials, v. 23, n. 13, pp. 2783-2788, Jul. 2002.

[32] CZARNECKA, B., NICHOLSON, J.W., "Ion release by resin modified glass ionomer cements into water and lactic acid solutions", Journal of Dentistry, vol. 34, n. 8, pp. 539-543, Feb. 2006.

[33] SRINIVASAN, K., RECHNITZL, G.A., "Reaction rate measurements with fluoride ion selective membrane electrode. Formation kinetics of ferrous fluoride and aluminum fluoride complexes", Analytical Chemistry, vol. 40, n. 12, pp. 1818-1825, Oct. 1968.

[34] NICHOLSON, J.W., CZARNECKA, B., "Review Paper: Role of aluminum in glass ionomer dental cements and its biological effects", Journal of Biomaterials Applications, vol. 24, n. 4, pp. 293-308, Nov. 2009.

[35] HADLEY P.C., MILELLA E., GERARDI C., et al., " Distribution of fluoride in glass ionomer cement determined using SIMS”, Biomaterials, v. 22, n. 12, pp. 1563-1569, Jun. 2001. 